\title{
Profile of drug interactions in hospitalized children
}

Jacqueline MARTINBIANCHO, Joice ZUCKERMANN, Luciana DOS SANTOS, Mariane M. SILVA.

\begin{abstract}
${ }^{\star}$
Introduction: The expected therapeutic response may be affected by the presence of drug interactions. With the high number of reports on new drug interactions, it has been difficult for health professionals to keep constantly updated. For this reason, computer systems have helped identify such interactions.

Objectives: To verify the rate and profile of drug interactions in medical prescriptions to hospitalized pediatric patients.

Methods: A descriptive study investigated prescriptions to hospitalized pediatric patients. The study included patients between 0 and 12 years old, containing 4 or more drugs in their prescriptions. The analysis of interaction and incompatibility possibilities in prescribed drugs used Micromedex / Drug-Reax ${ }^{\circledR}$ program.

Results: From 2005 to 2006, 3,170 patients were investigated, and 11,181 prescriptions were analyzed, a mean value of 3.5 prescriptions/patient. In total, 6,857 drug interactions were found, which corresponds to 1.9 interaction/prescription. Among them, relevance to ampicillin and gentamicin, found in 220 (3.2\%) prescriptions. In total, 2,411 drug incompatibilities in via y were found, a mean value of 0.5 /prescription, with emphasis on vancomycin and cefepime, found in $243(10.0 \%)$ prescriptions. Conclusion: The presence of drug interactions is a permanent risk in hospitals. This way, the utilization of computer programs, pharmacotherapy monitoring of patients and the pharmacist presence in the multidisciplinary team are some manners of contributing to hospitalized patients' treatment.
\end{abstract} Pharmacists. Brazil.
Keywords: Drug Interactions. Inpatients.

\section{RESUMEN}

Introducción: La respuesta terapéutica esperada puede modificarse por la presencia de interacciones medicamentosas. Con el elevado número de comunicaciones de nuevas interacciones medicamentosas, ha sido difícil para los profesionales de la salud mantenerse constantemente actualizados. Por este motivo, los ordenadores han ayudado a identificar estas interacciones.

Objetivos: Verificar la tasa y el perfil de las interacciones medicamentosas en las prescripciones médicas a pacientes pediátricos hospitalizados. Métodos: Un estudio descriptivo investigó las prescripciones a pacientes pediátricos hospitalizados. El estudio incluyó pacientes entre 0 y 12 años, que tenían 4 o más medicamentos en sus prescripciones. El análisis de las interacciones y las incompatibilidades posibles en los medicamentos prescritos utilizó el programa Micromedex / Drug$\operatorname{Reax}{ }^{\circledR}$.

Resultados: De 2005 a 2006, se investigó a 3.170 pacientes y se analizaron 11.181 prescripciones con una media de 3,5 recetas/paciente. En total se encontraron 6.857 interacciones medicamentosas, que corresponden a 1,9 interacciones/prescripción. Entre ellas, se encontró relación a ampicilina y gentamicina en $220(3,2 \%)$. En total, se encontraron 2.411 incompatibilidades de vía, con una media de 0,5 por prescripción, con énfasis en vancomicina y cefepime, encontradas en 243 (10,0\%).

Conclusión: La presencia de interacciones medicamentosas es un riesgo permanente en hospitales. Así que, la utilización de un programa informático, el seguimiento farmacoterapéutico de los pacientes y la presencia de un farmacéutico en el equipo multidisciplinario son algunas de las maneras de mejorar el tratamiento de los pacientes hospitalizados.

Palabras clave: Interacciones medicamentosas. Hospitalizados. Farmacéuticos. Brasil.

\section{(English)}

\footnotetext{
*Jacqueline MARTINBIANCHO. Pharmacist. Pharmacy Service, Hospital de Clínicas de Porto Alegre-RS (Brazil). Joice ZUCKERMANN. Pharmacist. Drug Information Center of the Hospital de Clínicas de Porto Alegre-RS (Brazil).

Luciana DOS SANTOS. Pharmacist. Pediatric Unit, Hospital de Clínicas de Porto Alegre-RS (Brazil). Mariane M. SILVA. Scholarship in Pharmaceutics. Hospital de Clínicas de Porto Alegre-RS (Brazil).
}

\section{INTRODUCTION}

The concomitant and extended utilization of two or more drugs in a treatment, either due to the patient's pathological condition or the need for action or effect complementation, is known as polypharmacy. The isolated utilization of such drugs 
may bring numerous benefits, but the expected therapeutic response may be affected by the presence of drug interactions. The main causes of hospital admissions and mortalities are related to drug interactions and their corresponding adverse effects. $^{1,2}$

Drug interactions refer to the interference of a drug in the action of another drug or the interference of food or nutrient in the action of drugs. ${ }^{2-4}$ It is estimated that interactions occur in 3 to $5 \%$ of patients receiving few drugs, and when 10 to 20 drugs are used, this rate reaches $20 \%$.

They can be divided into pharmaceutical pharmacokinetic or pharmacodynamic ${ }^{3,5}$ interactions. Pharmaceutical interactions, known as drug incompatibilities, occur before the drug administration in the body, when two or more of them are mixed in the same serum accessory, syringe or other recipient, and are evidenced by organoleptic alterations, reduced or interrupted activity of one or both drugs or formation of a new compound. Pharmacokinetic interactions occur during drug absorption, distribution, biotransformation and excretion processes, resulting in increased or reduced plasmatic concentration and consequently alteration to the pharmacological effect. Pharmacodynamic interactions are responsible for synergism and antagonism effects among drugs, and occur at their action sites. $^{3-5}$

Drug interactions may produce beneficial or desirable, or undesirable or harmful effects. ${ }^{4}$ The beneficial effects are those whose purpose is to treat concomitant diseases, enhancing the effectiveness, reducing adverse effects and allowing to reduce the dose, while the undesirable effects may reduce the drug effectiveness, and may produce adverse and even toxic effects in the body, besides increased treatment cost. The undesirable interactions may result in different impacts on the patient. They are subdivided into severe interactions, which may produce a risk to life or permanent damages, moderate interactions, which require additional treatment, and mild interactions, which do not affect significantly the therapy effect. ${ }^{6}$

Pediatric patients require special attention from health professionals in terms of drug interactions, as they react to drugs differently from adults. The body parts that are responsible for the excretion and elimination processes are not fully developed until 1 year of age, resulting in extended half-life of metabolized drugs and reduced excretion, which may result in toxicity problems. ${ }^{4,5,7}$

Regarding the treatment of a drug interaction occurrence that may be harmful to the patient, the health professional should: avoid complex therapeutic systems, adopt alternative measures, provide instructions on the correct interval between drug administrations, determine the probability of important interaction occurrences and monitor the patient. $^{5,7}$

With the high number of reports on new drug interactions, it has been difficult for health professionals to keep constantly updated. Today, computer systems are used to verify the risk of potential drug interactions, thus preventing the utilization of drugs that cause important and harmful interactions and reducing the patient's exposure to them. For this reason, the purpose of this study was to verify the rate and profile of drug interactions in medical prescriptions to hospitalized pediatric patients.

\section{METHODS}

A descriptive study was performed from January of 2005 to December of 2006 to verify the rate of drug interactions and its clinical meaning in medical prescriptions to pediatric patients during the hospitalization period at a Brazilian teaching hospital, which has 750 beds, 71 of them dedicated to pediatric patients.

The study included hospitalized patients between 0 and 12 years old, containing 4 or more drugs in their medical prescriptions, excluding the topical drugs (ointments, creams, ear drops, eye drops). The study excluded patients hospitalized in emergency areas, intensive care unit and oncology unit. Mean length-of-stay of patients hospitalized in pediatric unit is approximately 5 days.

The selected patients were investigated during the hospitalization period. Their electronic prescriptions were analyzed 3 times a week by a pharmacist and 2 scholarship holders in Pharmaceutics. The analysis of interaction and incompatibility possibilities in via y among prescribed drugs was performed through Micromedex/Drug-Reax® program. Based on the interactions found in the prescriptions, an analysis was performed on their relevance to the patient's current situation, and after that, the medical teams were informed using the standard service form of the hospital's pharmaceutical area.

For the purposes of this study, the drug interactions found and informed to the medical teams were classified in terms of interaction severity, effect start and literature documentation.

The interaction effect start classification is important for defining the treatment of interaction consequences to the patient. The consequences can have a 'fast' start, when the effects are evident within 24 hours and a prompt intervention is required, or a 'delayed' start, when the effects can take days or weeks to be evident. However, they may not be specified in the literature, due to insufficient studies. ${ }^{1,3,7}$

Regarding the interaction effect severity, the interactions can be classified as severe, when they can affect the clinical evolution or promote permanent damages to the patient, requiring intervention(s) to minimize or prevent serious effects; 'moderate', when the effects can produce aggravations or clinical alterations, requiring changes in the therapy, and 'mild', when they are not significant to affect the patient's therapy, as they result in mild or inconvenient effects, and do not require a greater therapy intervention. ${ }^{1,3,7}$ 
The biomedical-based literature documentation shows the possibility of drug interaction occurrences and the alterations they may cause to the patients' clinical responses. They are classified as 'excellent documentation', when the studies have clearly established the interaction existence; 'welldocumented', when they strongly suggest the interaction existence, but there are not many controlled studies supporting it; 'satisfactory documentation', when it is insufficient, but presents pharmacological considerations on the interaction existence; 'insufficient documentation', when there are few studies and the reported cases are limited; and 'improbable documentation', when it is insufficient and without pharmacological base.,

The study was approved by the Research Ethics Commission and presents a Commitment Term for data utilization exclusively for scientific publication purposes.

\section{RESULTS}

From 2005 to 2006, 3,170 patients were investigated and 11,181 prescriptions were analyzed, mean value of 3.5 prescriptions/patient. The mean quantity of items per prescription was 10 .

These prescriptions presented 6857 drug interactions, being 1.9 interaction/prescription and approximately 7 interactions/patient. Table 1 shows the most frequent drug interactions in the prescriptions. Among them, ampicillin and gentamicin were found in 220 (3.2\%) prescriptions, diazepam and chloral hydrate in $215(3.1 \%)$ and valproic acid and phenobarbital in 214 (3.1\%) prescriptions.

\begin{tabular}{|l|c|c|c|c|}
\hline \multicolumn{7}{|c|}{ Table 1 - Frequency of drug interactions found in medical prescriptions } \\
\hline \multicolumn{1}{|c|}{ Drug interactions } & $\mathrm{n}(\%)$ & Effect start & Severity level & Documentation \\
\hline Ampicillin + Gentamicin & $220(3.2 \%)$ & Fast & Mild & Good \\
\hline Diazepam + Chloral Hydrate & $215(3.1 \%)$ & Not specified & Severe & Satisfactory \\
Valproic Acid + Phenobarbital & $214(3.1 \%)$ & Delayed & Moderate & Good \\
Diazepam + Phenobarbital & $168(2.5 \%)$ & Not specified & Severe & Good \\
Phenobarbital + Chloral Hydrate & $164(2.4 \%)$ & Not specified & Severe & Satisfactory \\
\hline Phenytoin + Acetaminophen & $161(2.3 \%)$ & Delayed & Moderate & Good \\
\hline Dipyrone + Furosemide & $140(2.0 \%)$ & Delayed & Moderate & Not informed \\
\hline Carbamazepine + Acetaminophen & $138(2.0 \%)$ & Delayed & Moderate & Good \\
\hline Phenobarbital + Prednisolone & $127(1.9 \%)$ & Delayed & Moderate & Insufficient \\
\hline Diazepam + Phenytoin & $111(1.6 \%)$ & Delayed & Moderate & Good \\
\hline Total & $6857(100 \%)$ & & & \\
\hline
\end{tabular}

In total, 1,201 (5.6\%) drug interactions were notified to medical teams, being 204 (17\%) of severe level, $672(56 \%)$ of moderate level and $325(27 \%)$ of mild level.

Regarding drug incompatibilities in $y$-site, or pharmaceutical interactions, 2,411 incompatibilities were found, a mean value of $0.5 /$ prescription. Table 2 shows the most frequent incompatibilities found in the prescriptions. Among them, incompatibilities between vancomycin and cefepime in 243 (10.0\%) prescriptions, ampicillin and gentamicin in 216 $(9.0 \%)$ and cefepime and metoclopramide in 175 $(7.2 \%)$ prescriptions were more relevant.

\section{DISCUSSION}

This study utilized a computer system to verify the possibilities of drug interactions in medical prescriptions to pediatric patients and warned the medical teams, by means of pharmaceutical intervention through a differentiated form in the folders of patients exposed to such interactions. ${ }^{8-10}$ Although the number of clinically relevant drug interactions is considered as low, many hospital admissions are linked with effects caused by the interactions of utilized drugs.

The computer systems used to verify the possibilities of drug interactions are well described in the literature as a way to help health professionals prevent severe-level interactions and adverse effects with potential risks.

\begin{tabular}{|c|c|c|}
\hline Drug incompatibilities & $\mathrm{n}$ & $\%$ \\
\hline Cefepime + Vancomycin & 243 & 10.1 \\
\hline Ampicillin + Gentamicin & 216 & 9.0 \\
\hline Cefepime + Metoclopramide & 175 & 7.2 \\
\hline Ampicillin + Metoclopramide & 121 & 5.0 \\
\hline Furosemide + Metoclopramide & 91 & 3.8 \\
\hline Potassium Chloride + Diazepam & 89 & 3.7 \\
\hline Amikacin + Ceftazidime & 47 & 1.9 \\
\hline Cefepime + Diazepam & 47 & 1.9 \\
\hline $\begin{array}{l}\text { Piperacillin/Tazobactam } \\
\text { Vancomycin }\end{array}$ & 44 & 1.8 \\
\hline Gentamicin + Oxacillin & 44 & 1.8 \\
\hline Others & 1294 & 53.7 \\
\hline Total & 2411 & 100 \\
\hline
\end{tabular}

The probability of drug interaction occurrences increases in patients that receive 10 or more drugs. In this study, the obtained drug interaction rate was $61.3 \%$, with mean quantity of 10 items/analyzed prescription.

According to the analysis, due to the number of prescribed drugs, most patients presented one or more potential drug interactions, with mean value of $1.9 /$ prescription, which may reach higher values. ${ }^{1,10}$

Regarding the severity of interactions, $17 \%$ of all detected interactions were considered at severe level, which could consequently promote or cause permanent damages to patients; $56 \%$ of the interactions were considered as moderate, indicating that the treatment could have an 
impacted or different therapeutic response from the expected reaction, due to a drug intervention in the action of another drug.

Concerning the drug interactions found at higher frequency in the prescriptions, the pharmacodynamic interactions between aminoglycoside and beta-lactam antibiotics are well described in terms of their synergism effects. Regarding the concomitant administration of such drugs, fast and mild effects are observed in the patients, which may cause aminoglycoside antibiotics to lose their effectiveness through a chemical inactivation caused by beta-lactam antibiotics. ${ }^{5}$ For this reason, it is suggested to monitor the serum effects of aminoglycoside antibiotics in patients, and the concomitant administration of aminoglycoside and beta-lactam antibiotics through intravenous system should be avoided, allowing intervals of 1-2 hours between them ${ }^{7,10}$; also because of the frequent drug incompatibilities of aminoglycoside antibiotics with other drugs.

Chloral hydrate, a non-diazepam sedative drug, and benzodiazepam drugs may produce effects of respiratory depression, as the effect start is not specified in the literature and because it is a severelevel interaction, which requires the respiratory depression monitoring when such drugs are combined.

The concomitant utilization of valproic acid and phenobarbital in $30-50 \%$ of the patients results in a well-documented interaction in literature considered at moderate level and delayed effect start. The interaction result, an enzymatic induction through Cytochrome P450, generates elevated serum levels of phenobarbital and reduced effects of valproic acid, through the drug metabolism induction.,12 Dose adjustment is recommended in order to avoid toxicity. ${ }^{13}$
Incompatibilities between 2 or more drugs indicate that they should be administered separately in order to avoid drug effectiveness loss. Vancomycin and cefepime are antibiotics that depend on their concentration to ensure a safe administration. The administration of vancomycin at $5-10 \mathrm{mg} / \mathrm{mL}$ concentration with $20 \mathrm{mg} / \mathrm{mL}$ of cefepime is physically incompatible in via $\mathrm{y}$, and it may produce disturbances right after the mixture is done and the development of precipitates within a 4-hour period at ambient temperature. ${ }^{14}$

Cefepime and metochlopramide are physically incompatible, and they may result in disturbances right after they are mixed in via y or concomitantly.

\section{CONCLUSIONS}

The presence of drug interactions is a permanent risk in hospitals and the utilization of computer programs has become the most effective way to identify and treat them. Then, we can conclude that continued education, computer system for prescriptions, pharmacotherapy monitoring of patients and the pharmacist participation in the multidisciplinary team are some manners of improving the treatment to hospitalized patients. After the intervention, the drug interactions found in the prescriptions were analyzed every time administration by nurses and pharmacists, allowing intervals between them to minimize the effects.

\section{ACKNOWLEDGMENTS}

Funding from Research Fund of the University of Rio Grande do Sul (FIPE/HCPA) supported the research and publication.

\section{CONFLICT OF INTEREST}

None declared.

\section{References}

1. Cruciol-Souza JM, Thomson JC. A pharmacoepidemiologic study of drug interactions in a Brazilian teaching hospital. Clinics 2006; 61(6): 515-20.

2. Hohl CM, Dankoff J, Colacone A, Afilalo M.Polypharmacy, adverse drug-related events, and potential adverse drug interactions in elderly patients presenting to an emergency department. Ann Emerg Med 2001;38(6):666-71.

3 Tatro DS. Drug Interaction Facts. St. Louis: Facts \& Comparisons; 2006.

4 Sehn R, Camargo AL, Heineck I, Ferreira MBC. Interações medicamentosas potenciais em prescrições de pacientes hospitalizados. Infarma 2003; 15(9/10): 77-81.

5 Castro CGS, Teixeira CC. In "Interações Medicamentosas". Fuchs FD, Wannmacher L, Ferreira MB. Farmacologia Clínica - Fundamentos da Terapêutica Racional. $3^{a}$ ed. Rio de Janeiro: Guanabara Koogan, 2006. p.67-72.

6 Lisboa SML. In "Interações e Incompatibilidades Medicamentosas". Gomes MJVM, Reis AMM. Ciências Farmacêuticas Uma Abordagem em Farmácia Hospitalar. 1 ed. São Paulo: Atheneu, 2000. p.147-62Guanabara Koogan, 2000. p.14762.

7 Novaes MRC, Gomes KLG. Estudo de utilização de medicamentos em pacientes pediátricos. Infarma 2006; 18(7/8): 1820.

8 Malone DC, Hutchins DS, Haupert H, Hansten P, Duncan B, Van Bergen RC, Solomon SL, Lipton RB. Assessment of potential drug-drug interactions with a prescription claims database. Am J Health Syst Pharm 2005;62(19):1983-91.

9 Becker ML, Kallewaard M, Caspers PW, Schalekamp T, Stricker BH. Potential determinants of drug-drug interaction associated dispensing in community pharmacies. Drug Saf. 2005; 28(5): 371-8.

10 Mendes BG, Meiners MMMA. Prescrição de Medicamentos para Crianças Hospitalizadas: Como Avaliar a Qualidade? Rev Ass Med Brasil. 2001; 47(4): 332-7.

11 Abarca J, Colon LR, Wang VS, Malone DC, Murphy JE, Armstrong EP. Evaluation of the performance of drug-drug interaction screening software in community and hospital pharmacies. J Manag Care Pharm. 2006: 12(5): 383-9. 
Martinbiancho J, Zuckermann J, Dos Santos L, Silva MM. Profile of drug interactions in hospitalized children. Pharmacy Practice 2007;5(4):157-161.

12 Perucca E. Clinically relevant drug interactions with antiepileptic drugs. Br J Clin Pharmacol. 2005; 61(3): 246-55.

13 Riva R, Albani F, Contin M, Baruzzi A. Pharmacokinetic interactions between antiepileptic drug-clinical considerations. Clin Pharmacokinet. 1996; 31(6): 470-93.

14 Trissel LA. Handbook on Injectable Drugs. 13ª ed. Bethesda (MD): ASHP, 2005. p. 1446-59. 